\title{
İstanbul Kentinde Silivri - Sabiha Gökçen Havalimanı Arası Ulaşım Alternatiflerinin AHP TOPSIS Yöntemleri ile Analizi
}

\author{
Ömer Faruk Görçün \\ Kadir Has Üniversitesi \\ ORCID: 0000-0003-3850-6755
}

Öz

Bu çalışmada İstanbul kenti özelinde kentin iki en uzak noktası olan Silivri ve Sabiha Gökçen Havalimanları arasında ulaşım olanakların ve tercih edilecek ulaşım alternatiflerinin kullanıcılar tarafindan seçilmesine etki eden faktörleri analiz etmeyi hedeflenmektedir. Bu sayede en optimal ulaşım olanakları belirlenerek bu alternatiflerin geliştirilmesi olanaklı olabilecektir. Her iki nokta arasındaki ulaşım alternatifleri ve kullanicuların tercihlerine etki eden kriterlerin belirlenmesi ile ilgili olarak Çok Kriterli Karar Verme (ÇKKV) yöntemleri arasında yer alan Analitik Hiyerarşi Prosesi (AHP) ve İdeal Çözüme Benzerlik Yaklaşımı Tekniği (TOPSIS) yöntemleri seçilmiş, bu yöntemler kullanılarak belirlenen karar noktalar ve kriterler analiz edilmiştir. Bu çalışma literatürde görülen eksikliklerin giderilmesi açısından katkı sağlayacă̆ı gibi, kentsel ulaşım sistemlerinde kullanuclar, operatörler ve kamu otoriteleri için elde edilecek sonuçların son derece ilgi çekebileceği, karar alıcıların ulaştırma ile ilgili karar alırken bu çalışmanın sonuçların dikkate alacakları düşünülmektedir. Nihai olarak, elde edilen sonuçlar çerçevesinde ulaşım yatırımların daha rasyonel bir temelde gerçekleştirilebilmesi için ulaşım yatırımları ile ilgili karar alıcilara en uygun ulaşım alternatifleri ve kullanıcıların ulaşım türü seçiminde önem verdikleri kriterler gösterilmeye çalışılmıştır.

Anahtar Kelimeler: Ulaşım sistemleri, TOPSIS, kent içi yolcu taşımacılı̆̆ı.

idealkent (c) Kent Araştırmaları Dergisi (Journal of Urban Studies)

http://idealkentdergisi.com

Geliş Tarihi Received Date: 15.05.2018 Kabul Tarihi Accepted Date: 23.03.2018 


\title{
Analysis of Transportation Alternatives between Silivri - Sabiha Gökçen Airport in Istanbul by AHP-TOPSIS Methods
}

*

\author{
Ömer Faruk Görçün \\ Kadir Has University \\ ORCID: 0000-0003-3850-6755
}

\begin{abstract}
In this study, it has been aimed that urban transportation options that available between Silivri town and Sabiha Gökçen Airport and factors that affect the user's preferences were tried to analyze. by this means, determining the optimal transportation alternatives may be possible and these urban transport options can be developed. The Analytic Hierarchy Process theory and Technique for Order Preference by Similarity to Ideal Solution (TOPSIS) method were selected that are of the multi-criteria decision-making methodologies in order to deter-mine the criteria and decision options relating to urban transportation between these points and criteria and decision alternatives were analyzed with these methods. As well as this study may provide a contribution to remove the inadequacies in literature, it is considered that obtained results can be very attractive for public authorities, operators, and users in the urban transport systems. When a decision is taken, decision-makers should take into consideration the results of this research. Finally, most preferable urban transportation options and criteria that given more importance by users were tried to show to the decision makers who relating to determine the transport policy in Istanbul city in order to take more rational decisions that concerning with transportation investments.
\end{abstract}

Keywords: Transportation systems, TOPSIS, urban passenger transportation. 


\section{Giriş}

Kentlerin ekonomik, Sosyal ve kültürel gelişmesinin en önemli unsurlarından birisi; kentin sahip olduğu kentsel ulaşım faaliyetleri ve olanaklarıdır. Aynı zamanda kentsel ulaşım olanakları ve alternatifleri kentsel alanların gelişmişlik düzeyinin de bir göstergesi olarak kabul edilebilir. Ulaşım olanaklarını da etkileyecek şekilde kentler günümüzde ciddi problemlerle karşı karşıyadır. Bu problemlerin başında hızlı ve plansız ya da yeterli düzeyde planlı olmayan kentleşmenin yanı sıra, kırsal alanlardan kentsel alanlara gerçekleşen iç göçlere ek olarak, çeşitli nedenlerle ülke d1şından kentsel alanlara yönelen göçlerin artan bir biçimde yoğunlaşması ile doğumlar sonucu giderek daha büyük bir problemlere yol açan nüfus artışları ve kent kaynaklarının yetersiz kalması gibi problemler gelmektedir. Kentsel alanlarda gözlemlenen problemleri en yoğun biçimde yaşayan kentlerin başında İstanbul gelmektedir. İstanbul'da son yıllarda kayda değer bir ivme gösteren hızlı ve plansız kentleşme beraberinde kentsel alanlarda yoğunlaşan inşaat faaliyetleri ve dikey kentleşmeye yönelik yaklaşımlar İstanbul kentinde söz konusu problemlerin etkisini daha artırabilmektedir. Buna ek olarak İstanbul kentinde söz konusu olan problemlerin etkide bulunduğu alanlardan birisi de kentsel ulaşım olarak değerlendirilebilir. Kent merkezilerinde artan konut envanterine bağlı olarak, yaşayan nüfusun giderek artması kentin dışa doğru büyümesi yerine içe doğru çekilmesine yol açmış, konut, iş merkezleri, alışveriş merkezleri vb. gibi kentsel alanlardan yaşayan bireylerin gereksinim duyacakları tüm unsurların kentsel alan içerisinde rasyonel bir temelde yayılması yerine, belirli merkezlerde toplanması sonucunu ortaya çıkarmıştır. Bunun doğal bir sonucu olarak kentsel ulaşım sistemleri de verimli ve etkin bir nitelik göstermediği gibi, kentin ulaşım potansiyelini kısıtlayan doğal nitelikte bir takım sınırlılıklar da söz konusudur. Bunların başında; İstanbul kentinin kuzey ve güneyinin karasal ulaşım açısından yeterli olanaklara sahip olmamakla birlikte, kent içerisinde doğu - batı eksenli iki ana arter ile ulaşım sağlanması gelmektedir. Bu durum; söz konusu arterler üzerinde kaza vb. yavaşlatıcı etkenlerin meydana gelmesi durumunda kentsel ulaşımı son derece güçleştirebilmekte, trafiğin by-pass edilmesine olanak sağlayacak alternatif yolların son derece sınırlı olması problemin şiddetini artırabilmektedir. 
İstanbul kenti doğu batı eksenli bir ulaşım sistemine sahip olan ve coğrafi koşullar nedeniyle kentin kuzey ve güney ekseninde ulaşım olanaklarının son derece sınırlı olduğu bir şehirdir. Aynı zamanda kentin İstanbul boğazı ile ikiye ayrılması sonucunda Asya ve Avrupa yakaları arasında ulaşım bir takım kısıt ve sınırlılıklara sahiptir. İstanbul kentinde ulaşım aktiviteleri değerlendirildiğinde kent içinde yaşayan bireyler ağırlıklı olarak çalışmak için ev ve işyerleri arasında seyahat ettikleri görülmekte, bunu eğitim amaciyla öğrencilerin seyahatleri izlemektedir. Öte yandan çalışmak için yolculuk yapan bireylerin kat ettikleri mesafeler diğer amaçlarla seyahat eden bireylerden daha uzun olabilmektedir.

Gelişmişlik düzeyi dikkate alındığında İstanbul'da ulaşım olanakları kentin gelişim düzeyi ile uyumlu görünmemektedir. Son yıllarda artan kamu yatırımlarına rağmen kent içi ulaşım giderek daha problemli hale gelerek, kent içi akış hızı giderek azalım göstermiş, 2016 yılında kısmi bir iyileşme ile ortalama hız 67 km/s e ulaşmıştır (İBB, 2016, s.29).

İnşaat ve nüfus açısından kentin giderek gelişmesi ve genişlemesi ile paralel düzeyde ilerleyebilecek bir ulaşım sisteminin oluşturulması imkan dahilinde görülmemektedir. Bunun yerine var olan sistemlerin etkin biçimde kullanılması ve optimal bir eksende yeniden yapılandırılmaları problemin çözümünde etkili sonuçlar ortaya koyabilme potansiyeline sahiptir. Bu nedenle ulaşım sistemlerinin etkinlik ve verimliliklerinin analiz edilmesinin yanı sıra kullanıcıların tercihlerinin tespit edilebilmesi son derece değerli ve kıt kamu kaynaklarının rasyonel düzeyde ulaşım alternatiflerine yönlendirilmesine olanak sağlayabilir.

$\mathrm{Bu}$ doğrultuda en yoğun yolcu taşıma potansiyeline sahip iki nokta arasında mevcut ulaşım olanak ve alternatiflerinin değerlendirilmesi optimal kararların alınabilmesi konusunda hayati düzeyde öneme sahip bir husustur. Bu perspektifte mevcut tüm alternatiflerin ve bu alternatiflerin kullanıcılar tarafından tercih edilmesine etki eden faktör ve kriterlerin değerlendirilmesi gerekli olan bir yaklaşım olabilecektir.

Bu kapsamda söz konusu karar noktalarının ve karar noktalarına etki eden kriterlerin saptanması için uzmanlardan oluşan beş kişilik bir grup ile çeşitli düzeyde beyin fırtınası ve yuvarlak masa toplantılarından oluşan çalışmalar gerçekleştirilmiş, bunun sonucunda kentsel ulaşım alternatifleri ile ilgili tercihlere etki eden kriterler; ulaşım hızı, hizmet verme sıklığı, ulaşım hizmetine erişim olanakları, aktarmanın daha kolay ve az sayıda olması, düşük ulaşım ücretleri, ulaşım süresi, konfor gibi kriterler belirlenmiştir. 
Belirlenen kriterler arasında yer alan konfor ve güvenlik gibi sayısal ölçekte olmayan faktörlerin sayısal değerlere dönüştürülebilmesi amacıyla, kriterlerin göreli üstünlük ve önem derecelerinin belirlenmesi için ikili karşılaştırma soruları hazırlanmış ve bu sorular toplam 165 deneğe (kullanıcı) sorulmuştur. Elde edilen sonuçlar AHP metodolojisi ile değerlendirilmiş, her bir kriter için sayısal önem değerleri saptanmıştır.

Seçilen iki nokta arasındaki ulaşım alternatiflerine bakıldığında; toplam on üç farklı ulaşım alternatifi saptanmıştır. Bu alternatifler aşağıda listelenmiştir. Tablo-1 de gösterildiği gibi ulaşım alternatifleri farklı ulaştırma sistemlerinin kombinasyonlarından oluşmakta, her bir alternatif için değişmekle birlikte, otobüs, Marmaray, metro ve tramvay ile hafif raylı sistemler (LRT) gibi kent içi raylı sistemler, şehir hatları ve deniz otobüsleri gibi denizyolu yolcu taşımacılığının yanı sıra, IETT hat otobüslerinin oluşturduğu ulaşım opsiyonları görülebilmektedir.

Seçilen ulaşım alternatiflerinin her birisi için tercihlere etki edebilecek kriterler belirlenirken, bu kriterlerin etki düzeylerinin saptanabilmesi için de kullanıcılara sormak üzere ikili karşılaştırma anketleri hazırlanmış aynı zamanda değerlendirmeye alınan her bir için kriter ulaşım alternatifleri çerçevesinde sayısal değerler belirlenmiştir.

Özellikle ulaşım sitemlerinin hızları ölçülmek istendiğinde pik saatler olarak adlandırılan trafiğin en yoğun olduğu saatler seçilerek, internet üzerinde yer alan uygulamalar ile ortalama seyahat süreleri belirlendiği gibi, olası sapmaları tespit etmek üzere değerlendirmeye alınan ulaşım alternatifi doğrudan kullanılarak ölçümleme gerçekleştirilmiştir. Her bir alternatifte kullanılan ulaşım sistemlerinin kombinasyonları gözden geçirilerek, durak sayısı, hareket ve bekleme süreleri ile her bir etapta ulaşım aracının kat ettiği mesafe ölçülmüştür. 
Tablo 1. Silivri - Sabiha Gökçen Havalimanı Arası Ulaşım Kombinasyonları

\begin{tabular}{|c|c|c|c|c|c|c|c|c|c|c|c|c|c|}
\hline A & Çıkış & No & Durak & No & Durak & No & Durak & No & Durak & No* & Durak & No & Durak \\
\hline 1 & Silivri & 303B & Medipol & $31 Y$ & Ulubatlı & M1A & Yenikap1 & Marmaray & Yenikap1 & M4 & Yenisahra & E11 & S.Gökçen \\
\hline 2 & Silivri & 303 & Beylikdüzü & $34 \mathrm{BZ}$ & Cevizlibağ & $\mathrm{T} 1$ & Eminönü & Vapur & Kadıköy & SG1 & S.Gökçen & E11 & S.Gökçen \\
\hline 3 & Silivri & $300 \mathrm{G}$ & Tüyap & $34 \mathrm{C}$ & Cevizlibağ & $\mathrm{CMC}$ & K.çeşme & Marmaray & A.çeşme & M4 & Yenisahra & E11 & S.Gökçen \\
\hline 4 & Silivri & 300 & Tüyap & $34 \mathrm{C}$ & Ataköy & TYT & Bakırköy & Denizoto & Kadıköy & E11 & S.Gökçen & & \\
\hline 5 & Silivri & 303B & Kemalpaşa & $141 \mathrm{M}$ & M.köy & $34 \mathrm{AS}$ & S.çeşme & Minibüs & Bahçeler & E11 & S.Gökçen & & \\
\hline 6 & Silivri & 303 & K.çekmece & 34 & Z.kuyu & 251 & Med. Ün. & E11 & S.Gökçen & & & & \\
\hline 7 & Silivri & $300 \mathrm{G}$ & B.çekmece & 401 & K.çekmece & 34 & Z.kuyu & 251 & Med. Ün. & E11 & S.Gökçen & & \\
\hline 8 & Silivri & 303 & K.çekmece & $34 \mathrm{AS}$ & S.çeşme & E11 & S.Gökçen & & & & & & \\
\hline 9 & Silivri & 303 & Şirinevler & $34 \mathrm{C}$ & Ataköy & M1A & Yenikap1 & Marmaray & A.çeşme & E11 & S.Gökçen & & \\
\hline 10 & Silivri & 303 & K.çekmece & DK & Meydan & BN1 & Bakırköy & Denizoto & Kadıköy & E11 & S.Gökçen & & \\
\hline 11 & Silivri & 303 & Beylikdüzü & $34 \mathrm{C}$ & Cevizlibağ & $\mathrm{T} 1$ & Karaköy & Vapur & Kadıköy & E11 & & & \\
\hline 12 & Silivri & 303 & K.çekmece & 34 & İncirli & $97 \mathrm{~A}$ & Eminönü & E11 & S.Gökçen & & & & \\
\hline 13 & Silivri & 303 & K.çekmece & DK & Meydan & BN1 & Bakırköy & Denizoto & Bostanc1 & E9 & S.Gökçen & & \\
\hline 14 & Silivri & 303 & Beylikdüzü & $34 \mathrm{BZ}$ & Cevizlibağ & $500 \mathrm{~T}$ & Tuzla & E9 & S.Gökçen & & & & \\
\hline
\end{tabular}

* İstanbul kentinde söz konusu güzergâh üzerinde kullanılan otobüs ve diğer sistemlerin numaralarını göstermektedir. 
Elde edilen değerler çerçevesinde kat edilen mesafe ulaşım süresine bölünerek ortalama hız değerine ulaşılmıştır. Aynı zamanda ulaşım alternatifi içerisinde yer alan aktarmalar dikkate alınarak aktarma yapabilmek için yürünmesi gereken mesafe ve süre de belirlenmiş, bu mesafe ve süreye göre ulaşım alternatifinin erişim olanakları belirlenmiştir.

Ulaşım alternatiflerinin aktarma sayısını belirlemek üzere değiştirilen ulaşım türü ve araç sayısı dikkate alınmış her bir ulaşım alternatifi için buna göre aktarma sayıları saptanmıştır. Belirlen noktalar arasında ödenecek ulaşım ücreti her bir değiştirilen ulaşım türü ile aktarmalarda ödenecek ücretlere göre belirlenmiş, bunların toplamı alınarak her bir ulaşım alternatifinin ulaşım ücretleri belirlenmiştir. Konfor için ise kullanıcılara hangi taşıma türlerinin daha konforlu olduğu ikili karşılaştırma soruları yöneltilmiş, alınan cevapların geometrik ortalaması alınmıştır. Elde edilen her bir ulaşım türü için sayısal değer ulaşım türünün kat ettiği mesafe ile çarpılarak elde edilen sonuçlar toplanmış ve her bir ulaşım alternatifi için toplam konfor düzeyi saptanmıştır. Son olarak, ulaşım alternatiflerinin çevreye etkileri değerlendirilmiş, her bir kombinasyonda kullanılan ulaşım türü çerçevesinde birim emisyon değerleri ile kat edilen mesafe çarpılarak elde edilen değerlerin toplamı ulaşım alternatifinin çevresel etkileri olarak değerlendirilmiştir.

\section{Yöntem}

Çalışmanın amacı İstanbul kentinde en uzak iki nokta olan Silivri ve Sabiha Gökçen Havalimanı arasında kentsel ulaşımın sağlandığı ulaşım alternatiflerinin ve bu alternatiflerin kullanıcılar tarafından tercih edilmesine etki eden faktörlerin AHP ve TOPSIS yöntemleri kullanılarak belirlenmesidir. Bunun sonucunda en uygun alternatifin belirlenerek, bu ulaşım alternatifinin geliştirilmesi ve etkinlik ve verimlilik düzeyinin artırılabilmesi olanaklı olabilecektir. Kullanılan bu iki yöntemde kriterler arasinda değerlendirme yapılırken kararı verecek olan kişinin yargısı da devreye girmektedir (Dündar ve Ecer, 2008, s.198).

Farklı seçim kriterlerinin ve alternatiflerin bulunması çok kriterli karar verme yöntemlerini kullanmayı gerektirmektedir. Buna bağlı olarak hem nicel hem de nitel değerlerin mevcut olması uygulamada AHP ve TOPSIS yöntemlerinin birlikte kullanılmasını zorunlu hale getirmiştir. Uygula- 
mada belirlen 14 farklı ulaşım alternatifinin 9 farklı tercih kriteri çerçevesinde değerlendirilmesi ve en uygun ulaşım alternatifinin belirlenmesinin yanı sıra, tüm alternatiflerin sayısal temelde önem derecelerine göre sıralanmaları mümkün olabilecektir.

Çalışmanın perspektifinde kullanılan yöntem olarak TOPSIS metodu; Yoon ve Hwang tarafından geliştirilen çok kriterli bir karar verme metodolojisidir (Chen, 2000, s. 2). Yöntemin temel yaklaşımı karar noktalarının ideal çözüme yakın olup olmadığıdır. Dolayısıyla yöntemin temeli, pozitif ideal çözüme en yakın mesafe ve negatif ideal çözüme en uzak mesafedeki alternatifi seçmeye dayanmaktadır (Ertuğrul ve Özçil, 2014) Uygulama toplamda altı adımdan oluşmaktadır (Erdoğan, 2010).

TOPSIS yönteminin birinci aşamasında A olarak adlandırılan karar matrisleri oluşturulmakta, bu matris aynı zamanda başlangıç matrisi olarak da tanımlanmaktadır. Karar matrisinin satırları değerlendirmeye alınan karar noktalarından oluşurken, sütunlar tercihlere etki eden kriterlerden oluşmaktadır. Dolayısıyla A matrisinde m sayıda alternatif ile n sayıda kriterden meydana gelmektedir.

$$
A_{i j}=\left[\begin{array}{cccc}
a_{11} & a_{12} & \ldots & a_{1 n} \\
a_{21} & a_{22} & \ldots & a_{2 n} \\
\cdot & & & \cdot \\
\cdot & & & \cdot \\
\cdot & & & \cdot \\
a_{m 1} & a_{m 2} & \ldots & a_{m n}
\end{array}\right]
$$

Uygulamanın ikinci aşamasında standart karar matrisleri oluşturulmaktadır. Standart karar matrisi R olarak adlandırılırken, bu aşamada gerçekleştirilen işlem normalizasyon olarak da tanımlanabilmektedir. Bunun için aşağıdaki formül kullanılmaktadır (Ustasüleyman, 2009, s. 37).

$$
r_{i j}=\frac{a_{i j}}{\sqrt{\sum_{k=1}^{m} a_{k j}^{2}}}
$$


Normalizasyon işleminde her bir değer sütunda yer alan değerlerin karelerinin hesaplanması ve karelerinin toplamının karekök değerinin bulunması ile gerçekleştirilmektedir. Bu işlemden sonra her bir matris bileşeni bulunduğu sütuna ilişkin elde edilen karekök değerine bölünerek $R$ matrisi elde edilmektedir. Uygulamada formül 1 kullanılmakta ve bütün matris bileşenleri için işlem tamamlandıktan sonra Standart karar matrisine ulaşılmaktadır.

$$
R_{i j}=\left[\begin{array}{cccc}
r_{11} & r_{12} & \ldots & r_{1 n} \\
r_{21} & r_{22} & \ldots & r_{2 n} \\
\cdot & & & \cdot \\
\cdot & & & \cdot \\
\cdot & & & \cdot \\
r_{m 1} & r_{m 2} & \ldots & r_{m n}
\end{array}\right]
$$

TOPSIS yönteminin üçüncü aşamasında elde edilen standart karar matrisleri kullanılarak ağırlıklı standart karar matrisleri oluşturulmaktadır. Gerçekleştirilen işlemler soncunda elde edilen bu matris aynı zamanda $\mathrm{V}$ matrisi olarak da adlandırılmaktadır. Bu aşamada öncelikli olarak her bir kriter için ağırlık değeri $\left(w_{i}\right)$ belirlenmektedir. Ağırlık değeri bir kriterin diğerlerine kıyasla önem değerini de göstermektedir. Bütün kriterlerin ağırlık değerlerinin toplamı bir değerini almak zorunda olduğundan her bir kriter 0 ile 1 arasında bir ağırlık değeri almaktadır. Her bir kriter için w değeri belirlendikten sonra R matrisinin her bir bileşeni kendi sütunu için saptanmış ağırlık değeri ile çarpılmakta ve V matrisi oluşturulmaktadır.

$$
V_{i j}=\left[\begin{array}{cccc}
w_{1} r_{11} & w_{2} r_{12} & \ldots & w_{n} r_{1 n} \\
w_{1} r_{21} & w_{2} r_{22} & \ldots & w_{n} r_{2 n} \\
\cdot & & & \cdot \\
\cdot & & & \cdot \\
\cdot & & & \cdot \\
w_{1} r_{m 1} & w_{2} r_{m 2} & \ldots & w_{n} r_{m n}
\end{array}\right]
$$


TOPSİS yönteminde, ideal çözüm için gerekli olan yakınlık bulunurken hem pozitif ideal çözüme uzaklık hem de negatif ideal çözüme uzaklık dikkate alınmaktadır.Bu uzaklıklar yardımıyla elde edilen yakınlık katsayıları kullanılarak sıralama yapılmaktadır (Janko ve Bernroider, 2005). Dördüncü aşamada pozitif ve negatif ideal çözümler oluşturulmaktadır. TOPSIS yöntemi her bir karar noktası ve karara etki eden kriterin maksimum ve minimum arasında yer alan değerler aldığını varsaymakta ve her bir alternatifiler arasında en iyi çözüme en yakın olan alternatif diğerlerine kıyasla optimal çözüm olarak değerlendirilebilmektedir. Bu aşamada değerlendirmeye alınan kriterlerden bazıları minimize değerler aldığında en yüksek faydayı sağlarken, bazılarının da en yüksek faydayı sağlaması için maksimize edilmesi gerekebilmektedir. İdeal çözümler oluşturulabilmesi için aşağıdaki formülden yararlanılmaktadır.

$$
A^{*}=\left\{\left(\max _{i} v_{i j} \mid j \in J\right),\left(\min _{i} v_{i j} \mid j \in J^{\prime}\right\}\right.
$$

Formül 2 en yüksek değere ulaştığında en yüksek faydayı sağlayacak kriterler için kullanılmaktadır. Bunun için elde edilen ağırlıklı standart karar matrislerinin her bir sütun değerleri içerisinde yer alan en yüksek değer ideal maksimum çözüm olarak belirlenmektedir. Yukarıdaki formül kullanılarak hesaplanacak set $A^{*}=\left\{v_{1}^{*}, v_{2}^{*}, \ldots, v_{n}^{*}\right\}$ şeklinde gösterilmektedir. Değerlendirmeye alınan kriterin en yüksek faydayı sağlaması için en küçük değeri alması gerekiyor ise aynı şekilde V matrisinin sütun değerleri içerisinde en küçük değer ideal minimum çözüm olarak belirlenebilir. Bunun için aşağıdaki formül kullanılmaktadır.

$$
A^{-}=\left\{\left(\min _{i} v_{i j} \mid j \in J\right),\left(\max _{i} v_{i j} \mid j \in J^{\prime}\right\}\right.
$$

Formül 3 kullanılarak hesaplanacak set $A^{-}=\left\{v_{1}^{*}, v_{2}^{*}, \ldots, v_{n}^{*}\right\}$ şeklinde gösterilmektedir. İkinci formülde de yer alan $J$ değeri maksimum faydayı gösterirken, $J$ 'ise minimum kayıp, maliyet ya da katlanılacak bedeli göstermektedir.

Metodolojinin beşinci adımında pozitif ve negatif ideal çözüme yakınlıklarının belirlenmektedir. TOPSIS yöntemi her bir karar noktasının ideal çözüme yakınlık derecesine göre öncelik değerinin belirlenebilmesi için 
elde edilen değerlerin ideal çözümlerden ne ölçüde sapma gösterdiğinin belirlenmesi gerekmektedir. Bunun için Euclidian Uzaklık Yaklaşımından yararlanılmaktadır. Bu yaklaşım çerçevesinde elde edilen sapma değerleri ideal ayrım $S_{i}^{*}$ ve negatif ideal ayrım $S_{i}^{-}$ölçeği olarak tanımlanmaktadır. Her iki değerin hesaplanması için kullanılacak formüller aşağıda gösterilmektedir. Hesaplanacak olan $S_{i}^{*}$ ve $S_{i}^{-}$değerleri değerlendirmeye alınan karar noktası sayısı kadar olmak zorundadır.

$$
\begin{aligned}
& S_{i}^{*}=\sqrt{\sum_{j=1}^{n}\left(v_{i j}-v_{j}^{*}\right)^{2}} \\
& S_{i}^{-}=\sqrt{\sum_{j=1}^{n}\left(v_{i j}-v_{j}^{-}\right)^{2}}
\end{aligned}
$$

TOPSIS yönteminin altıncı ve son aşamasında her bir karar noktası için ideal çözüme yakınlık derecesi hesaplanmaktadır. Her bir karar noktasının ideal çözüme göreli yakınlığı $\left(C_{i}^{*}\right)$ alacağı değerler 0 ila 1 arasında olmaktadır. Bir karar noktası için önem verilen en iyi çözüm minimum değer alması gereken bir çözüm ise değerinin sıfıra yakın olması, maksimum değer alması gereken bir çözüm ise 1 e yakın olması gerekmektedir. Aşağıdaki formül kullanılarak her bir alternatif için en iyi çözüm değerleri hesaplanabilmektedir.

$$
C_{i}^{*}=\frac{S_{i}^{-}}{S_{i}^{-}+S_{i}^{*}}
$$

\section{TOPSIS Yöntemi ile Ulaşım Alternatif ve Seçim Kriterlerinin Değerlendirilmesi}

Çalışmada İstanbul kentinde en uzak iki nokta olarak değerlendirilen Silivri ve Sabiha Gökçen Havalimanı arasında ulaşım alternatifleri ile kullanıcıların tercihlerine etki eden kriterler ve faktörler değerlendirilmiş, her iki nokta arasında en iyi ulaşım alternatifi ve kombinasyonları saptanmaya çalışılmıştır. Uygulamada mevcut tüm ulaşım kombinasyonları ele alınarak en yoğun kullanıldığ düşünülen opsiyonlar belirlenirken, bu opsiyonların tercih edilmesine etki eden kriterler de saptanmıştır. Buna göre 
seçilen iki nokta arasında toplam on dört ulaşım kombinasyonu ile yedi kriter belirlenmiştir. Değerlendirilmek üzere seçilen tüm ulaşım alternatifleri tablo-1 de gösterilmektedir. Dolayısıyla alternatif olarak A I'den $^{\prime}$ A 14'e kadar opsiyonlar sıralandırılmıştır. Kriterler ise $\mathrm{C}_{1}{ }^{\prime}$ den $\mathrm{C}_{9}$ 'ye kadar tanımlanmaktadır.

$\mathrm{C}_{1}$ olarak tanımlanan hızlı ulaşım olanakları kriterinin sayısal değerlerini hesaplamak üzere iki nokta arası kat edilen mesafe, güzergah kat etme süresine bölünmüş, her bir ulaşım alternatifi için elde edilen değerler hız olarak tanımlanmıştır. Ulaşım alternatiflerinin sık hizmet verme değerlerini $\left(\mathrm{C}_{2}\right)$ hesaplamak üzere ulaşım opsiyonları içerisinde yer alan ulaşım sistemlerinin tarifelerinde gösterilen sefer aralıkları baz alınmış, her bir kombinasyonda çok sayıda farklı ulaşım sistemleri kullanıldığından bunların ortalaması sıklık değeri olarak belirlenmiştir. Aktarma ( $\left.C_{3}\right)$ ise kullanıcıların tercih edecekleri bir ulaşım alternatifinde kaç kez ulaşım araç ve sistemi değiştirdikleri ile ilişkili bir kriterdir. Erişim olarak bahsedilen kriter; kullanıcıların ulaşım hizmetlerine ulaşabilme olanaklarının yanı sıra, ulaşım için katlandıkları kısıt ve sınırlılıkları ifade etmektedir. Erişim kriterinin sayısal olarak tanımlanabilmesi için her bir ulaşım alternatifinde kullanıcıların ulaşım sistemlerine erişmek için yürüyerek kat ettikleri mesafe ve süre dikkate alınmış, sürelerin toplamı alınarak her bir alternatif için sayısal ölçekte erişim değeri belirlenmiştir.

Ücretin belirlenmesi ile ilgili olarak, her bir alternatifte taşıma türü değişimi sırasında kullanıcıların ödeyecekleri ulaşım ücretlerinin toplamı alınarak ücret kriteri hesaplanmıştır. Buna göre İstanbul kentinde ulaşım araçları için farklı ücretler uygulanabilmekte, özel hat olarak tanımlanan ulaşım sistemlerinde artan tarifeli ücret alınabilirken, standart IETT ulaşım araçlarında ilk kullanımda belirli bir ücret alınırken, aktarmalarda azalan ölçekli bir ücretlendirme söz konusu olmaktadır. Örnek olarak ilk kullanımda tam ücret olan 2,6 TL ücret alınırken, birinci aktarmada 1,85 TL, ikinci aktarmada 1,40 TL, sonraki aktarmalarda 0,90 TL ücret alınmaktadır. Buna ek olarak bazı İETT hatlarında çift bilet uygulaması söz konusu olmakta, hangi duraktan binilirse binilsin çift bilet bedeli olan 5,2 TL alınmaktadır. 
Tablo-2 Ulaşım Alternatifleri ve Kriterleri Tablosu

\begin{tabular}{|c|c|c|c|c|c|c|c|c|c|c|}
\hline & & \multicolumn{9}{|c|}{ Kriterler } \\
\hline & & $\mathrm{Hiz}$ & Siklık & Aktarma & Erişim & Ücret & Süre & Güvenlik & Çevre & Konfor \\
\hline & & $\mathrm{C}_{1}$ & $\mathrm{C}_{2}$ & $\mathrm{C}_{3}$ & $\mathrm{C}_{4}$ & $\mathrm{C}_{5}$ & $\mathrm{C}_{6}$ & $\mathrm{C}_{7}$ & $\mathrm{C}_{8}$ & $\mathrm{C}_{9}$ \\
\hline Alternatif-1 & $\mathrm{A}_{1}$ & 40,9 & 8,57 & 6 & 23 & 18,75 & 203 & 0,2182 & 173,5651 & 0,0571 \\
\hline Alternatif-2 & $\mathrm{A}_{2}$ & 28,9 & 13,67 & 5 & 24 & 14,45 & 245 & 0,2243 & 254,6133 & 0,2068 \\
\hline Alternatif-3 & $\mathrm{A}_{3}$ & 38,7 & 8,83 & 6 & 17 & 17,95 & 205 & 0,2151 & 129,3574 & 0,2007 \\
\hline Alternatif-4 & $\mathrm{A}_{4}$ & 32,2 & 44,35 & 5 & 28 & 20,40 & 198 & 0,2270 & 270,1776 & 0,1942 \\
\hline Alternatif-5 & $\mathrm{A}_{5}$ & 37,6 & 12,60 & 5 & 21 & 17,05 & 198 & 0,2293 & 150,0140 & 0,1861 \\
\hline Alternatif-6 & $\mathrm{A}_{6}$ & 31,2 & 15,75 & 4 & 77 & 19,80 & 224 & 0,2300 & 141,3632 & 0,1851 \\
\hline Alternatif-7 & $\mathrm{A}_{7}$ & 31,2 & 12,00 & 5 & 77 & 20,85 & 223 & 0,2301 & 140,8826 & 0,1847 \\
\hline Alternatif-8 & $\mathrm{A}_{8}$ & 32,8 & 11,33 & 3 & 20 & 13,80 & 193 & 0,1540 & 130,0157 & 0,1933 \\
\hline Alternatif-9 & A9 & 37,2 & 8,20 & 5 & 18 & 17,05 & 209 & 0,2160 & 170,0960 & 0,1799 \\
\hline Alternatif-10 & $\mathrm{A}_{10}$ & 31,5 & 45,95 & 5 & 24 & 20,40 & 230 & 0,2309 & 284,9560 & 0,1684 \\
\hline Alternatif-11 & $\mathrm{A}_{11}$ & 29,4 & 12,40 & 5 & 18 & 17,85 & 233 & 0,2247 & 250,1678 & 0,1912 \\
\hline Alternatif-12 & $\mathrm{A}_{12}$ & 29,8 & 10,25 & 4 & 20 & 15,65 & 213 & 0,2327 & 127,5326 & 0,1474 \\
\hline Alternatif-13 & $\mathrm{A}_{13}$ & 32,6 & 44,55 & 5 & 20 & 20,40 & 218 & 0,2324 & 282,3127 & 0,1657 \\
\hline Alternatif-14 & $\mathrm{A}_{14}$ & 36,10 & 10,50 & 4 & 23 & 19,80 & 226 & 0,2300 & 165,3932 & 0,2189 \\
\hline
\end{tabular}

812 idealkent 
Süre kriteri belirlenen iki nokta arasında belirli bir ulaşım alternatifini kullanan kullanıcının çıkış noktasından varış noktasına ulaşana kadar yolda geçireceği süreyi ifade etmektedir. Her bir opsiyon için süre ulaşım kombinasyonunda yer alan ulaşım sistem ve türlerinin kendi etaplarını kat etmek için gereken sürenin yanı sıra, söz konusu ulaşım araçlarına ulaşabilmek için kullanıcıların yürüdükleri mesafede geçen sürelerin toplamından oluşmaktadır.

Güvenlik kriterinin sayısal ölçekte tanımlanabilmesi için kullanıcılara ulaşım sistemlerini güvenlik açısından Saaty'nin 1-9 skalasına göre puanlamaları istenmiş, elde edilen değerlerin geometrik ortalamaları alınarak ikili karşılaştırma matrisleri oluşturulmuş, bu matrisler kullanılarak matrisler normalize edilmiş ve AHP yöntemi her bir alternatif için güvenlik değerleri 0 ile 1 arasında değerler olarak hesaplanmıştır. Ulaşım alternatiflerinde farklı ulaşım sistemlerinin kombinasyonları söz konusu olduğundan, her bir ulaşım sistemi ile kat edilen mesafe ile söz konusu değerin çarpımı güzergâhın toplam mesafesine bölünmüş, birim mesafe için bir güvenlik değeri hesaplanmıştır.

Çevreye duyarlılık ile ilgili kriterin sayısal ölçekte tanımlanabilmesi için ulaşım alternatifleri içerisinde yer alan her bir ulaşım sisteminin birim emisyon değerleri belirlenmiş, güzergah boyunca salınımda bulunacakları emisyon değerlerinin toplamı alınarak, her bir ulaşım alternatifi için toplam emisyon salınım değeri, dolayısıyla çevresel duyarlılık düzeyi hesaplanmıştır (Tablo-3).

Tablo-3 Ulaşım Türleri Emisyon ve Enerji Tüketim Değerleri

\begin{tabular}{|l|c|c|}
\hline \multicolumn{1}{|c|}{ Ulaşım Sistemi } & Emisyon Değeri & Tüketim Değeri \\
\hline Özel Hat Otobüsleri & $2,67 \mathrm{~g} / \mathrm{lt}$ & $0,45 \mathrm{lt} / \mathrm{km}$ \\
\hline Metrobüs & $2,67 \mathrm{~g} / \mathrm{lt}$ & $0,50 \mathrm{lt} / \mathrm{km}$ \\
\hline İETT Otobüs & $2,67 \mathrm{~g} / \mathrm{lt}$ & $0,45 \mathrm{lt} / \mathrm{km}$ \\
\hline Tramvay & $0,4 \mathrm{~g} / \mathrm{kWh}$ & $4,5 \mathrm{kWh} / \mathrm{km}$ \\
\hline Metro & $0,4 \mathrm{~g} / \mathrm{kWh}$ & $3,5 \mathrm{kWh} / \mathrm{km}$ \\
\hline Şehir Hatları Vapur & $3,2 \mathrm{~g} / \mathrm{lt}$ & $100 \mathrm{~kg} / \mathrm{s}$ \\
\hline Denizotobüsü & $3,2 \mathrm{~g} / \mathrm{lt}$ & $200 \mathrm{~kg} / \mathrm{s}$ \\
\hline Marmaray & $0,4 \mathrm{~g} / \mathrm{kWh}$ & $3,5 \mathrm{kWh} / \mathrm{km}$ \\
\hline Minibüs & $2,67 \mathrm{~g} / \mathrm{lt}$ & $0,45 \mathrm{lt} / \mathrm{km}$ \\
\hline
\end{tabular}


Ulaşım kombinasyonları içerisinde yer alan ulaşım türlerinin kat ettikleri mesafe tüketim değerleri ve birim emisyon değerleri ile çarpıldığında her bir ulaşım sistemi için kullanıldığı güzergahta salınımda bulunacakları emisyon hesaplanabilmektedir. Deniz ulaşımında farklı olarak enerji tüketim değerleri mesafe ölçeğinde değil, saat başına verildiğinde ilgili güzergahın süresi dikkate alınarak harcanacak enerji miktarı belirlenmekte, elde edilen değer birim emisyon miktarı ile çarpılarak deniz araçlarının yol açacağı çevresel kirlenme düzeyi hesaplanabilmektedir. Sonuç olarak, her bir alternatifte yer alan ulaşım sistemlerinin emisyon salınım değerleri toplanarak güzergahta çevreye salınacak emisyon değerine ulaşlabilmektedir.

Bir başka kriter olan konfor için sayısal ölçekte değerler belirlenirken güvenlik kriterinin hesaplanmasında kullanılan yöntem kullanılmakta, kullanıcıların verdikleri yanıtlara göre her bir ulaşım alternatifi için kullanılan ulaşım sisteminin kat edeceği mesafe ve güzergahın toplam mesafesi dikkate alınarak her bir ulaşım opsiyonu için konfor seviyesi sayısal ölçekte tanımlanmaktadır.

Karar matrisi oluşturulurken, değerlendirmeye alınan ve karar noktaları olarak adlandırılan ulaşım alternatifleri satırları meydana getirirken, sütunlar ise ulaşım alternatiflerinin seçimi ile ilgili kullanıcıların dikkate aldıkları kriterlerden oluşmaktadır. Çalı̧̧mada toplam 14 ulaşım kombinasyonu ile 9 kriter tespit edilmiş, karar matrisi aşağıdaki gibi oluşturulmuştur.

\begin{tabular}{c|ccccccccc} 
& $C 1$ & $C 2$ & $C 3$ & $C 4$ & $C 5$ & $C 6$ & $C 7$ & $C 8$ & $C 9$ \\
$A 1$ & 40,9 & 8,57 & 6 & 23 & 18,75 & 203 & 0,218 & 173,6 & 0,057 \\
$A 2$ & 28,9 & 13,67 & 5 & 24 & 14,45 & 245 & 0,224 & 254,6 & 0,207 \\
$A 3$ & 38,7 & 8,83 & 6 & 17 & 17,95 & 205 & 0,215 & 129,4 & 0,201 \\
$A 4$ & 32,2 & 44,35 & 5 & 28 & 20,40 & 198 & 0,227 & 270,2 & 0,194 \\
$A 5$ & 37,6 & 12,60 & 5 & 21 & 17,05 & 198 & 0,229 & 150,0 & 0,186 \\
$A 6$ & 31,2 & 15,75 & 4 & 77 & 19,80 & 224 & 0,230 & 141,3 & 0,185 \\
$A=$ & 31,2 & 12,00 & 5 & 77 & 20,85 & 223 & 0,230 & 180,9 & 0,185 \\
$A 8$ & 32,8 & 11,33 & 3 & 20 & 13,80 & 193 & 0,154 & 130,0 & 0,193 \\
$A 9$ & 37,2 & 8,20 & 5 & 18 & 17,05 & 209 & 0,216 & 170,1 & 0,180 \\
$A 10$ & 31,5 & 45,95 & 5 & 24 & 20,40 & 230 & 0,231 & 284,9 & 0,168 \\
$A 11$ & 29,4 & 12,40 & 5 & 18 & 17,85 & 233 & 0,224 & 250,1 & 0,192 \\
$A 12$ & 29,8 & 10,25 & 4 & 20 & 15,65 & 213 & 0,233 & 127,5 & 0,147 \\
$A 13$ & 32,6 & 44,55 & 5 & 20 & 20,40 & 218 & 0,232 & 282,3 & 0,166 \\
$A 14$ & 36,1 & 10,50 & 4 & 23 & 19,80 & 226 & 0,230 & 165,4 & 0,219
\end{tabular}

Karar matrisi " $\mathrm{A}$ " elde edildikten sonra matris bileşenleri ikinci aşamada normalize edilmekte ve standart karar matrisi olarak adlandırılan $\mathrm{R}$ 
matrisine ulaşılmaktadır. Bu aşamada matris elemanlarının her birisi bulundukları sütundaki elemanları karelerinin toplamının kareköküne bölünmesi ile elde edilmektedir. Karar matrisinde yer alan her bir hücre değeri için bu işlem gerçekleştirilmekte ve aşağıda gösterilen $R$ matrisine ulaşılmaktadır.

\begin{tabular}{|c|c|c|c|c|c|c|c|c|c|}
\hline & $C 1$ & $C 2$ & $C 3$ & $C 4$ & $C 5$ & C6 & C7 & C8 & $C 9$ \\
\hline $\mathrm{A} 1$ & 0,3237 & 0,0988 & 0,3308 & 0,1742 & 0,2739 & 0,2511 & 0,2628 & 0,2319 & 0,0843 \\
\hline $\mathrm{A} 2$ & 0,2291 & 0,1576 & 0,2757 & 0,1818 & 0,2111 & 0,3030 & 0,2701 & 0,3403 & 0,3053 \\
\hline A3 & 0,3060 & 0,1019 & 0,3308 & 0,1288 & 0,2622 & 0,2536 & 0,2591 & 0,1729 & 0,2963 \\
\hline A4 & 0,2545 & 0,5115 & 0,2757 & 0,2121 & 0,2980 & 0,2449 & 0,2734 & 0,3611 & 0,2867 \\
\hline A5 & 0,2975 & 0,1453 & 0,2757 & 0,1591 & 0,2491 & 0,2449 & 0,2762 & 0,2005 & 0,2747 \\
\hline$A 6$ & 0,2470 & 0,1817 & 0,2205 & 0,5832 & 0,2893 & 0,2771 & 0,2771 & 0,1889 & 0,2733 \\
\hline$=A 7$ & 0,2472 & 0,1384 & 0,2757 & 0,5832 & 0,3046 & 0,2758 & 0,2771 & 0,1883 & 0,2726 \\
\hline$A 8$ & 0,2599 & 0,1307 & 0,1654 & 0,1515 & 0,2016 & 0,2387 & 0,1855 & 0,1737 & 0,2854 \\
\hline$A 9$ & 0,2942 & 0,0946 & 0,2757 & 0,1363 & 0,2491 & 0,2585 & 0,2602 & 0,2273 & 0,2656 \\
\hline$A 10$ & 0,2490 & 0,5300 & 0,2757 & 0,1818 & 0,2980 & 0,2585 & 0,2780 & 0,3808 & 0,2486 \\
\hline$A 11$ & 0,2325 & 0,1430 & 0,2757 & 0,1363 & 0,2608 & 0,2882 & 0,2706 & 0,3343 & 0,2822 \\
\hline$A 12$ & 0,2357 & 0,1182 & 0,2205 & 0,1515 & 0,2286 & 0,2635 & 0,2803 & 0,1704 & 0,2176 \\
\hline$A 13$ & 0,2576 & 0,5138 & 0,2757 & 0,1515 & 0,2980 & 0,2696 & 0,2799 & 0,3773 & 0,2447 \\
\hline$A 14$ & 0,2857 & 0,1211 & 0,2205 & 0,1742 & 0,2893 & 0,2795 & 0,2770 & 0,2210 & 0,3232 \\
\hline
\end{tabular}

Üçüncü aşamada elde edilen standart karar matrisinin sütun bileşenleri karar noktalarına etki eden her bir kriter için belirlenen AHP ağırlık değeri ile çarpılarak ağırlıklandırılmış karar matrisi olan $\mathrm{V}$ matrisi elde edilmektedir. Ağırlık değerleri $\left(w_{i}\right)$ kullanıcılara yöneltilen ikili karşılaştırma soruları sonucunda elde edilmiş yanıtların Analitik Hiyerarşi Prosesi yöntemi kullanılarak analiz edilmesi sonucunda belirlenmiştir. Buna göre 165 deneğe yöneltilen sorular sonucunda belirlenen ağırlık değerleri aşağıdaki tabloda gösterilmektedir.

Tablo-4 Seçim Kriterleri ve AHP Ağırlıkları

\begin{tabular}{lclclc}
\hline \multicolumn{1}{c}{ Kriter } & Ağırlık (w) & Kriter & Ağırlık (w) & Kriter & Ağırlık (w) \\
\hline Hız & 0,2622 & Erişim & 0,1325 & Güvenlik & 0,1012 \\
\hline Sıklık & 0,0688 & Ücret & 0,1241 & Çevre & 0,1095 \\
\hline Aktarma & 0,0743 & Süre & 0,0735 & Konfor & 0,0539 \\
\hline
\end{tabular}

R matrisinin bileşenleri kendi sütunları için saptanmış ağırlık değerleri ile çarpılarak V matrisi elde edilebilmektedir. 


$$
\begin{array}{c|ccccccccc|} 
& C 1 & C 2 & C 3 & C 4 & C 5 & C 6 & C 7 & C 8 & C 9 \\
\text { A1 } & 0,0849 & 0,0068 & 0,0246 & 0,0231 & 0,0340 & 0,0185 & 0,0266 & 0,0254 & 0,0045 \\
\text { A2 } & 0,0601 & 0,0108 & 0,0205 & 0,0241 & 0,0262 & 0,0223 & 0,0273 & 0,0373 & 0,0165 \\
\text { A3 } & 0,0802 & 0,0070 & 0,0246 & 0,0171 & 0,0325 & 0,0186 & 0,0262 & 0,0189 & 0,0160 \\
\text { A4 } & 0,0667 & 00352 & 0,0205 & 0,0281 & 0,0370 & 0,0180 & 0,0277 & 0,0395 & 0,0155 \\
\text { A5 } & 0,0780 & 00100 & 0,0205 & 0,0211 & 0,0309 & 0,0180 & 0,0279 & 0,0220 & 0,0148 \\
A 6 & 0,0648 & 0,0125 & 0,0164 & 0,0773 & 0,0359 & 0,0204 & 0,0280 & 0,0207 & 0,0147 \\
V= & 0,0648 & 0,0095 & 0,0205 & 0,0773 & 0,0378 & 0,0203 & 0,0280 & 0,0206 & 0,0147 \\
A 7 & 0,0682 & 0,0090 & 0,0123 & 0,0201 & 0,0250 & 0,0175 & 0,0188 & 0,0190 & 0,0154 \\
A 9 & 0,0771 & 0,0065 & 0,0205 & 0,0181 & 0,0309 & 0,0190 & 0,0263 & 0,0246 & 0,0143 \\
A 10 & 0,0653 & 0,0365 & 0,0205 & 0,0241 & 0,0370 & 0,0209 & 0,0281 & 0,0417 & 0,0134 \\
A 11 & 0,0610 & 0,0098 & 0,0205 & 0,0181 & 0,0324 & 0,0212 & 0,0274 & 0,0366 & 0,0152 \\
A 12 & 0,0618 & 0,0081 & 0,0164 & 0,0201 & 0,0284 & 0,0194 & 0,0284 & 0,0187 & 0,0117 \\
A 13 & 0,0676 & 0,0354 & 0,0205 & 0,0201 & 0,0370 & 0,0198 & 0,0283 & 0,0413 & 0,0132 \\
A 14 & 0,0749 & 0,0083 & 0,0164 & 0,0231 & 0,0359 & 0,0280 & 0,0280 & 0,0242 & 0,0174
\end{array}
$$

Uygulamanın dördüncü aşamasında ağırlıklı karar matrisinin (V) her bir sütünün bileşenlerinin maksimum ve minimum değerleri belirlenerek her bir kriter için ideal çözümler ve negatif ideal çözümler belirlenmektedir. Aşağıdaki formül kullanılarak değerlendirmeye alınan her bir kriter için ideal çözümlerin kümesi belirlenebilmektedir.

$$
\begin{aligned}
& A^{*}=\left\{\left(\max _{i} v_{i j} \mid j \in J\right),\left(\min _{i} v_{i j} \mid j \in J^{\prime}\right\}\right. \\
& A^{*}=\{0,0849 ; 0,0365 ; 0,0246 ; 0,0773 ; 0,0378 ; 0,0223 ; 0,0284 ; 0,0417 ; 0,0174\}
\end{aligned}
$$

Aynı şekilde negatif ideal çözümler belirlenmek istendiğinde aşağıdaki formül kullanılarak, ideal negatif değerlerin kümesi elde edilebilmektedir.

$$
\begin{aligned}
& A^{-}=\left\{\left(\min _{i} v_{i j} \mid j \in J\right),\left(\max _{i} v_{i j} \mid j \in J^{\prime}\right\}\right. \\
& A^{-}=\{0,0601 ; 0,0065 ; 0,0123 ; 0,0171 ; 0,0250 ; 0,0175 ; 0,0188 ; 0,0187 ; 0,0045\}
\end{aligned}
$$

Beşinci aşamada her bir alternatif için ideal ayrım ve negatif ideal ayrım değerleri hesaplanmaktadır. 4. ve 5. formüller kullanılarak hesaplama yapıldığında aşağıdaki gibi ideal ayrım ve negatif ayrım değerleri her bir alternatif için hesaplanabilmektedir. 


\begin{tabular}{c|ccccccccc|c} 
& $C 1$ & $C 2$ & $C 3$ & $C 4$ & $C 5$ & $C 6$ & $C 7$ & $C 8$ & $C 9$ & $i d$ \\
A1 & 0,00000 & 0,00088 & 0,00000 & 0,00294 & 0,00001 & 0,00001 & 0,000003 & 0,00027 & 0,00017 & 0,0654 \\
A2 & 0,00062 & 0,00066 & 0,00002 & 0,00283 & 0,00013 & 0,00000 & 0,000001 & 0,00002 & 0,00000 & 0,0654 \\
A3 & 0,00002 & 0,00087 & 0,00000 & 0,00363 & 0,00003 & 0,00001 & 0,000005 & 0,00052 & 0,00000 & 0,0713 \\
A4 & 0,00033 & 0,00000 & 0,00002 & 0,00242 & 0,00000 & 0,00002 & 0,000000 & 0,00000 & 0,00000 & 0,0529 \\
A5 & 0,00005 & 0,00070 & 0,00002 & 0,00316 & 0,00005 & 0,00002 & 0,000000 & 0,00039 & 0,00001 & 0,0662 \\
$A 6$ & 0,00040 & 0,00057 & 0,00007 & 0,00000 & 0,00000 & 0,00000 & 0,000000 & 0,00044 & 0,00001 & 0,0387 \\
$A 7$ & 0,00040 & 0,00073 & 0,00002 & 0,00000 & 0,00000 & 0,00000 & 0,000000 & 0,00044 & 0,00001 & 0,0400 \\
$A 8$ & 0,00028 & 0,00075 & 0,00015 & 0,00327 & 0,00016 & 0,00002 & 0,000092 & 0,00051 & 0,00000 & 0,0725 \\
$A 9$ & 0,00006 & 0,00090 & 0,00002 & 0,00351 & 0,00005 & 0,00001 & 0,000004 & 0,00028 & 0,00001 & 0,0695 \\
$A 10$ & 0,00038 & 0,00000 & 0,00002 & 0,00283 & 0,00000 & 0,00000 & 0,000000 & 0,00000 & 0,00002 & 0,0570 \\
$A 11$ & 0,00057 & 0,00071 & 0,00002 & 0,00351 & 0,00003 & 0,00000 & 0,000001 & 0,00003 & 0,00000 & 0,0698 \\
$A 12$ & 0,00053 & 0,00080 & 0,00007 & 0,00327 & 0,00009 & 0,00001 & 0,000000 & 0,00053 & 0,00003 & 0,0730 \\
$A 13$ & 0,00030 & 0,00000 & 0,00002 & 0,00327 & 0,00000 & 0,00001 & 0,000000 & 0,00000 & 0,00002 & 0,0601 \\
$A 14$ & 0,00010 & 0,00079 & 0,00007 & 0,00294 & 0,00000 & 0,00000 & 0,000000 & 0,00031 & 0,00000 & 0,0649
\end{tabular}

\begin{tabular}{c|ccccccccc|c} 
& $C 1$ & $C 2$ & $C 3$ & $C 4$ & $C 5$ & $C 6$ & $C 7$ & $C 8$ & $C 9$ & nid \\
A1 & 0,00062 & 0,00000 & 0,00015 & 0,00004 & 0,00008 & 0,00000 & 0,00006 & 0,00005 & 0,00000 & 0,0315 \\
A2 & 0,00000 & 0,00002 & 0,00007 & 0,00005 & 0,00000 & 0,00002 & 0,00007 & 0,00035 & 0,00014 & 0,0268 \\
A3 & 0,00041 & 0,00000 & 0,00015 & 0,00000 & 0,00006 & 0,00000 & 0,00006 & 0,00000 & 0,00013 & 0,0283 \\
A4 & 0,00004 & 0,00082 & 0,00007 & 0,00012 & 0,00014 & 0,00000 & 0,00008 & 0,00044 & 0,00012 & 0,0428 \\
A5 & 0,00032 & 0,00001 & 0,00007 & 0,00002 & 0,00003 & 0,00000 & 0,00008 & 0,00001 & 0,00011 & 0,0256 \\
$A 6$ & 0,00002 & 0,00004 & 0,00002 & 0,00363 & 0,00012 & 0,00001 & 0,00009 & 0,00000 & 0,00010 & 0,0634 \\
$A 7$ & 0,00002 & 0,00001 & 0,00007 & 0,00363 & 0,00016 & 0,00001 & 0,00009 & 0,00000 & 0,00010 & 0,0640 \\
$A 8$ & 0,00007 & 0,00001 & 0,00000 & 0,00001 & 0,00000 & 0,00000 & 0,00000 & 0,00000 & 0,00012 & 0,0141 \\
$A 9$ & 0,00029 & 0,00000 & 0,00007 & 0,00000 & 0,00003 & 0,00000 & 0,00006 & 0,00004 & 0,00010 & 0,0243 \\
$A 10$ & 0,00003 & 0,00090 & 0,00007 & 0,00005 & 0,00014 & 0,00001 & 0,00009 & 0,00053 & 0,00008 & 0,0435 \\
$A 11$ & 0,00000 & 0,00001 & 0,00007 & 0,00000 & 0,00005 & 0,00001 & 0,00007 & 0,00032 & 0,00011 & 0,0256 \\
$A 12$ & 0,00000 & 0,00000 & 0,00002 & 0,00001 & 0,00001 & 0,00001 & 0,00009 & 0,00000 & 0,00005 & 0,0138 \\
$A 13$ & 0,00006 & 0,00083 & 0,00007 & 0,00001 & 0,00014 & 0,00001 & 0,00009 & 0,00051 & 0,00007 & 0,0423 \\
$A 14$ & 0,00022 & 0,00000 & 0,00002 & 0,00004 & 0,00012 & 0,00001 & 0,00009 & 0,00003 & 0,00017 & 0,0262
\end{tabular}

Uygulamanın altıncı ve son aşamasında negatif ideal ayrımına ilişkin satır değerlerinin negatif ve pozitif ayrım değerlerinin toplamına bölünmesi ile her bir ulaşım alternatifinin alacağ mektedir. Elde edilen sonuçlar aşağıdaki gibi gösterilmektedir.

Tablo-5 Ulaşım Alternatifleri ve Kriterlere Göre Sıralandırılması

\begin{tabular}{ccc} 
Alternatifler & Sonuçlar & Siralama \\
\hline Alternatif 1 & 0,628723167 & 6 \\
\hline Alternatif 2 & 0,575495428 & 7 \\
\hline Alternatif 3 & 0,675328977 & 2 \\
\hline Alternatif 4 & 0,641213106 & 5 \\
\hline Alternatif 5 & 0,68439826 & 1 \\
\hline Alternatif 6 & 0,286035251 & 8 \\
\hline Alternatif 7 & 0,270247959 & 9 \\
\hline Alternatif 8 & 0,660497533 & 4 \\
\hline Alternatif 9 & 0,662817613 & 3 \\
\hline
\end{tabular}


Yukarıdaki tabloya göre en optimal sonucu veren ulaşım alternatifi Alternatif 5 olarak tanımlanan A5 alternatifidir. Bu ulaşım kombinasyonu; dört aktarmanın gerçekleştiği ve Silivri'den 303B nolu otobüs hattı ile başlayarak, Kemalpaşa durağında 141M nolu otobüs hattına aktarma yapılarak Mecidiyeköy'e ulaşılan kombinasyondur, bu duraktan da 34AS numaralı Metrobüs hattı ile Sögütlüçeşme durağına ulaşılmakta, bu duraktan minibüslerle Bahçeler durağına ulaşıldıktan sonra en son olarak E11 numaralı İETT otobüs hattı ile Sabiha Gökçen Havalimanına ulaşılabilmektedir.

A5 alternatifini sırasıyla A3, A9 ve diğerleri izlemekte, aralarındaki seçim önceliğine göre hiyerarşi $A 5>A 3>A 9>A 8>A 4>A 1>A 2>A 6>A 7$ şeklinde oluşturulabilmektedir.

\section{Sonuç}

İstanbul kentine en uzak iki nokta olmasının yanı sıra en yoğun kent içi yolcu taşımacılığına konu olan güzergahın başlangıç ve bitiş noktaları olarak değerlendirilebilecek Silivri ve Sabiha Gökçen Havalimanı arasında ulaşımın sağlanabileceği ulaştırma kombinasyonları farklı kriterler ve ölçekler dikkate alınarak, TOPSIS yöntemi ile değerlendirilmiş, bunun sonucunda tablo 1 de detayları gösterilen ulaşım alternatifi olan, A6 alternatifinin en optimal güzergah olabileceği değerlendirilmiştir.

Söz konusu güzergâh beş aktarmanın gerçekleştirildiği, hızın ortalama olarak $37,6 \mathrm{~km} / \mathrm{s}$ olduğu, ortalama 12,6 dakikada bir ulaşım hizmetinin verildiği ve aktarmaların yürünerek 21 dakikada gerçekleştirildiği bir güzergâhtır. Buna ek olarak başlangıçtan son noktaya kadar ödenecek ulaşım ücreti 17,05 TL olarak belirlenmiştir. Aynı zamanda toplam emisyon düzeyi 150, 01 gr $\mathrm{CO}_{2}$ olarak hesaplanmıştır.

Bütün olası ulaşım alternatifleri ve kombinasyonları değerlendirildiği zaman, 5. Alternatifin en iyi çözümü sağladığı onu 3. Alternatif ve diğerlerinin izlediği görülmektedir. Bunun yanı sıra, kullanıcı olarak tanımlanan 165 deneğe AHP yöntemi çerçevesinde hangi kriterlerin diğerlerine göre önemli ve öncelikli olduğu ikili karşılaştırma anketleri ile sorulmuş, bunun sonucunda elde edilen cevapların sayısal değerleri geometrik ortalama yöntemi ile ortalamaları alınarak, sabit bir değer elde edilmiştir.

Deneklerin verdikleri cevaplar çerçevesinde kriterlerin ağırlıkları hesaplandığında hızlı ulaşım \%26,2 ile değeri ile en fazla dikkate alınan kriter olarak belirlenmiş, ulaşım hizmetine erişim \%13,2 ile en çok dikkate 
alınan ikinci kriter olurken, onları \%12,4 ile ücret, \%10,9 ile çevreye duyarlılık, \%10,1 ile güvenlik kriterleri izlemektedir. En düşük önem derecesine sahip kriterler dikkate alındığında; konfor kriteri \%5,7 değeri almakta, hizmet verme sıklığı ise \%6,9 değeri almaktadır. Bunları \%7,3 ile ulaşım süresi, \%7,4 ile aktarma olanakları izlemektedir.

Sonuç olarak bakıldığında kullanıcılar en fazla ulaşım hızına ve hizmete erişim kriterlerine önem verirken, bu kriterlere bağlı olarak en yoğun talep göstermeleri beklenen ulaşım kombinasyonu A5 olarak gösterilen alternatif olarak değerlendirilebilmektedir. Bu sonuçlar çerçevesinde ulaşım kombinasyonları otobüs, metrobüs, otobüs, minibüs ve otobüs olarak görülebilmektedir. Diğer alternatifler içerisinde yer alan Marmaray ve metro ile deniz ulaşımı gibi alternatiflerin bulunduğu kombinasyonlar karayolu ile gerçekleştirilen taşıma kombinasyonlarına kıyasla yeterli düzeyde etkin ve verimlilik sağlayamamakta, kamu otoritesinin bu ulaşım alternatiflerini yeniden gözden geçirmesi gerekmektedir. 


\title{
Extended Abstract
}

\section{Analysis of Transportation Alternatives between Silivri - Sabiha Gökçen Airport in Istanbul by AHP-TOPSIS Methods}

*

\author{
Ömer Faruk Görçün \\ Kadir Has University
}

In this study, it has been aimed that urban transportation options that available between Silivri town and Sabiha Gökçen Airport and factors that affect the user's preferences were trying to analyze. By this means, determining the optimal transportation alternatives may be possible and these urban transport options can be developed. The Analytic Hierarchy Process theory and Technique for Order Preference by Similarity to Ideal Solution (TOPSIS) method were selected that are of the multi-criteria decision-making methodologies in order to determine the criteria and decision options relating to urban transportation between these points and criteria and decision alternatives were analyzed with these methods. Finally, most preferable urban transportation options and criteria that given more importance by users were trying to show the decision makers who relating to determining the transport policy in Istanbul city in order to take more rational decisions that concerning with transportation investments.

Public sources, which is extremely scarce and valued can be allocated properly to the right public transport systems in case public transport authorities aware of the user's choices. More importantly, effectivity and productivity analysis should be made by these authorities suitably. In this perspective, evaluation of transportation alternatives and opportunities between two points, where to have an urban transportation potential is a vital issue to take an optimal decision about urban transportation.

Thus, a board of experts consisted of five members was constructed by researchers in order to determine the selection criteria and decision alternatives about urban passenger transportation. Members of this working group were selected among professionals who work at least for fifteen years in the field of urban transportation as a senior executive in the public 
or private sector. Afterward round table meetings were organized and selection criteria and decision alternatives, which affect the user's choices have been determined by the board of experts as a result of these meetings. Selection criteria such as speed, the frequency of service, accessibility to transportation systems, the number of transfers, low fares, travel time, comfort have been determined by the members of the board of experts.

In order to convert some selection criteria, which are nonnumerical factors such as comfort and safety to numerical values, pairwise comparison questions have been prepared and these questions have been directed to the subject group consisted of 165 individuals. Obtained results have been evaluated by using the AHP method and numerical values for each factor have been calculated. When the transportation alternatives between the selected two points are considered fourteen transportation options have been determined. These alternatives consist of combinations of different urban transportation systems such as buses, rail systems, subways, seabuses, city line ferries.

Especially, peak traffic hours were selected in order to compute the speed of these transportation systems and combinations. Directly observations related speed of each transport alternative have been realized by using these alternatives by researchers. In addition to that, indirect observation has also been conducted by using some software and programs that operate via the internet. At the same time, the number of stops, waiting and operational times have been observed by evaluating all transport combinations. The total distance of each alternative is divided into transportation time and the average speed of each transport combinations is calculated. In addition to that, the number of transfer for each combination and required time for it have been determined.

In order to determine the best urban transportation alternatives in Istanbul city between farthest two points, a hybrid model, which consists of the AHP technique and TOPSIS method was constructed and implemented. While the AHP method was used in order to determine the numerical values for some non-numerical factors, the TOPSIS method was used to calculate the relative importance value of each decision option.

Determined nine selection criteria and fourteen decision options were analyzed by using constructed hybrid multi-criteria decision-making model in order to determine the best and proper urban passenger transportation alternative. Obtained results were reviewed by the board of experts to evaluate whether these outputs of this study are realistic or not. 
When the relative importance values of selection criteria are considered, the most important factor has been determined as the speed of transport alternative. The value of this criterion is $26.2 \%$ and it has the highest importance score. The second one is the accessibility of transport alternatives with a score of $13.2 \%$. While the third important factor is faring, the fourth important criterion is the environmental sensitivity of transport alternatives. Others such as comfort, service frequency, travel time, the number of transfer were determined as factors, which have lower importance values.

When all transportation alternatives and their combinations are evaluated, the best alternative is determined as the fifth option. This option consists of long-distance buses, bus rapid transport (BRT) systems, and short distance buses. Maritime transportation options such as city-line ferries and sea-buses are not evaluated as optimal transport systems by users. In addition to that, obtained results of multi-criteria decision making analysis using the TOPSIS method prove this approach. Therefore, it is very usual that individuals, who live in the urban area can make choices speedy transport alternatives compared to comfortable transport options. The second best alternative is the third options and it consists of the rail transport system called the Marmaray in addition to the same transport systems with the fifth alternative. The obligation of making a large number of transfers is the worst part of this transport combination.

As a consequence, individuals want to spend a minimum time during the travel in the urban areas and they don't give importance to some factors such as comfort and safety and low emissions compared to their demand about speed transport. Although these factors are important not only for societies but also for public authorities, they are not the priority factors for public transport systems users. Thus, public authorities should take into consideration these facts and should consider these kinds of requirements and need while they planning about transport systems and transport infrastructure.

\section{Kaynakça/References}

Chen, C.T. (2000). Extensions of the topsis for group decision-making under fuzzy environment, Fuzzy Sets and Systems, 114, 1-9. 
Erdoğan, S. (2010). Küresel kriz döneminde ihracat ve turizm gelirleri ile büyümenin Türkiye ekonomik performansına etkisi: Topsis yöntemi ile analiz. Sosyal Ekonomik Araştırmalar Dergisi, 10 (20), 219-232.

Ustasüleyman, T. (2009). Bankacılık sektöründe hizmet kalitesinin değerlendirilmesi: Ahs-Topsis yöntemi. Bankacular Dergisi, 69, 33-43.

Janko, W. ve Bernroider, E. (2005). Multi-criteria decision making: An application study of ELECTRE and TOPSIS. 09.10.2005 tarihinde www.ai.wuwien.ac.at/ bernroid/lehre/seminare/ws04/A7-TOPSIS-0107503.pdf adresinden erişildi.

Dündar S. ve Ecer F. (2008). Öğrencilerin GSM operatörü tercihinin analitik hiyerarşi süreci yöntemiyle belirlenmesi: Yönetim ve ekonomi. Celal Bayar Üniversitesi İ̈BF, 15 (1), 1-11.

Ertuğrul, İ. ve Özçil, A. (2014). Çok kriterli karar vermede TOPSIS ve VIKOR yöntemleriyle klima seçimi. Çankırı Karatekin Üniversitesi, İktisadi ve İdari Bilimler Fakültesi Dergisi, 4(1), 267-282.

İstanbul BüyükŞehir Belediyesi. (2016). İstanbul yılık ulaşım raporu 2016. 15.04.2018 tarihinde https://tuhim.ibb.gov.tr/media/2130/ibb ulasim raporu.pdf adresinden erişildi.

\section{Ömer Faruk Görçün}

Kadir Has Üniversitesi Uygulamalı Bilimler Fakültesi Dekan Yardımcısı ve Öğretim Üyesi Ömer Faruk Görçün, 1976 yılında İstanbul'da doğdu. 1999 yılında Trakya Üniversitesi Kamu Yönetimi Bölümü lisans, ardından aynı üniversitede Uluslararası ilişkiler alanında Yüksek Lisansını tamamlayan Ömer Faruk Görçün, Doktora çalışmalarını İstanbul Üniversitesi, Deniz Bilimler Enstitüsünde tamamlamıştır. Ömer Faruk Görçün iş hayatına Lojistik Sektöründe başladı. Sektörde önde gelen firmalarda üst düzey yönetici olarak çalışan Ömer Faruk Görçün İstanbul Üniversitesi ve Bahçeşehir Üniversitesinde Öğretim Üyeliği ve idari görevlerde bulunmuştur. Uluslararası ve ulusal birçok basılı esere sahip olan Ömer Faruk Görçün evli ve bir çocuk babasıdır.

Ömer Faruk Görçün who is an assistant professor and deputy dean of Faculty of Applied Science at Kadir Has University was born in Istanbul in 1976. after he completed the bachelor degree in 1999 in the fields of public administration at Trakya University he gained the master agree on the department of international relations at the same university. finally, he completed his doctoral studies on the Institute of marine science and administration at the Istanbul University. Görçün who took on tasks at several companies in the private sector as a senior executive carried out a duty at Istanbul and Bahcesehir Universities also as an executive.

E-mail: omer.gorcun@khas.edu.tr 